\title{
Potensi dan keragaman hayati cagar alam Bukit Bungkuk
}

\author{
Salman Yasir ${ }^{1}$, Eko Sutrisno ${ }^{2}$ \\ ${ }^{1}$ Balai Besar Konservasi Sumber Daya Alam Riau \\ ${ }^{2}$ Balai Penelitian dan Pengembangan Teknologi Serat Tanaman Hutan
}

\begin{abstract}
The area of Bukit Bungkuk wildlife sanctuary is on Kampar regency in Riau Province. Based on the decree of Minister of Forestry at 3917/Menhut-VII/KUH/2014 which were areas 12.828,88 Ha. The existence of Bukit Bungkuk wildlife sanctuary is a habitat for the endangered and the protected flora and fauna. Monitoring of the existence these areas was carried out in a rapid survey and interview with village officials and local communities. These activities to obtain the existence and the potential of carrying capacity of Bukit Bungkuk wildlife sanctuary. This area is a home to 32 species of wildlife found directly or indirectly. Furthermore, there are 2 potentials environmental services in this area that can be developed on empowerment schemes to the edging local community. The potentials of environmental services are Koto Panjang reservoir and several waterfalls around and in the area. Currently, the utilization of environmental services was carried out by the community and based on natural sustainability with the local wisdom principle.
\end{abstract}

Keywords: wildlife sanctuary; existence; environmental service; biodiversity; potency

Kawasan CA. Bukit Bungkuk ditunjuk sebagai kawasan cagar alam atas dasar keadaan alamnya. Karakteristik kawasannya mempunyai kekhasan tumbuhan, satwa, dan ekosistem yang perlu dilindungi agar terjaga kealamiannya. Kekhasan karakteristik kawasan ini terletak pada bentang alamnya yang mana bertipe hutan hujan dataran rendah dan perbukitan dengan keragaman hayati tinggi. Status kawasan dengan tujuan tertentu ini menjadi areal penyimpan plasma nutfah.

Kawasan CA. Bukit Bungkuk ini diharapkan mampu menjadi habitat untuk perlindungan flora dan fauna endemik Provinsi Riau secara khusus ataupun Indonesia secara umum. Kondisinya yang masih memiliki keterbatasan akan akses secara tidak langsung berkorelasi dengan komposisi rantai makanan di ekosistem hutan. Rantai makan berjalan secara alami dengan komposisi relatif seimbang dikarenakan minim atau bahkan tidak adanya campur tangan manusia. Selain itu, kawasan CA. Bukit Bungkuk menjalankan peran ekosistem sebagai (catchment area) penyangga sistem kehidupan di sekitarnya.

Menurut bentang topografi sendiri, kawasan CA. Bukit Bungkuk termasuk kawasan pada bagian hulu DAS Kampar dengan ancaman dan gangguan yang relatif besar. Selanjutnya mempertimbangkan posisi dan konturnya secara alami, kawasan CA. Bukit Bungkuk senantiasa terjaga agar performanya sebagai daerah tangkapan air dan atau limpasan Pembangkit Listrik Tenaga Air (PLTA) Koto Panjang yang berdampingan dapat beroperasi secara optimal.

Penunjukkan dan pemanfaatan kawasan dengan fungsi khusus dilakukan secara seksama dengan memperhatikan kondisi yang ada. CA. Bukit Bungkuk selain menjadi rumah, habitat dan daerah jelajah (home range) bagi segenap fauna dan flora. Eksistensi kawasan ini tentunya memiliki kemampuan secara ekosistem dalam menjalankan fungsi ekologisnya guna mendukung aktifitas makluk hidup di sekitarnya. Keberadaan dan fungsi tersebut senantiasa berpotensi untuk dikembangkan dan lebih lanjut dipelihara agar tetap berjalan sebagaimana mestinya dalam konsep ekosistem.

Monitoring terkait konsistensi kawasan CA Bukit Bungkuk harus dilakukan secara periodik. Selain sebagai upaya pencegahan adanya perusakan menggali potensi baru dan terbaharukan tentunya menjadi sebuah peluang dan tantangan untuk pengembangan berkesinambungan. Sehingga kebutuhan akan data mengenai status terkini berupa keragaman hayati yang ada, potensi ekologi dan daya dukung CA. Bukit Bungkuk itu dapat terdokumentasikan secara berkelanjutan. Melalui makalah ini akan dipaparkan potensi dan keanekaragaman hayati yang ada di CA. Bukit Bungkuk.

\section{METODA PENELITIAN}

Kegiatan inventarisasi keragaman hayati dan potensi ekologi dilakukan pada kawasan CA. Bukit Bungkuk dengan pendekatan keterwakilan karakteristik kawasan. Metode yang digunakan adalah sebagai berikut :

Rapid survey, yaitu pendataan menggunakan jalur-jalur yang sudah ada untuk mendata flora dan fauna yang dijumpai langsung maupun temuan organ tubuh dan kotorannya. 
Wawancara dengan penduduk setempat dan aparat desa guna mengumpulkan berbagai informasi terkait eksistensi kawasan dan potensi jasa lingkungan CA. Bukit Bungkuk serta potensi ancaman yang ada.

\section{HASIL DAN PEMBAHASAN}

\section{Bukit Bungkuk}

Kawasan konservasi CA. Bukit Bungkuk merupakan salah satu kawasan konservasi yang berada di bawah pengelolaan Balai Besar KSDA Riau yang terletak di Kecamatan Kuok, Kecamatan Salo, dan Kecamatan XII Koto Kampar, Kabupaten Kampar. Berdasarkan letak geografisnya, kawasan CA. Bukit Bungkuk berada pada koordinat $0^{\circ} 11^{\prime}-0^{\circ} 18^{\prime}$ LU dan $100^{\circ} 50^{\prime}-101^{\circ} 01^{\prime}$ BT. Kawasan ini ditunjuk berdasarkan Surat Keputusan Menteri Kehutanan No. 173/Kpts-II/1986 tanggal 6 Juni 1986 dengan luasan 20.000 hektar. Kawasan ini kemudian ditetapkan melalui Keputusan Menteri Kehutanan No. 3917/Menhut-VII/KUH/2014 tanggal 14 Mei 2014 dengan luasan 12.828,88 hektar (Gambar 1).

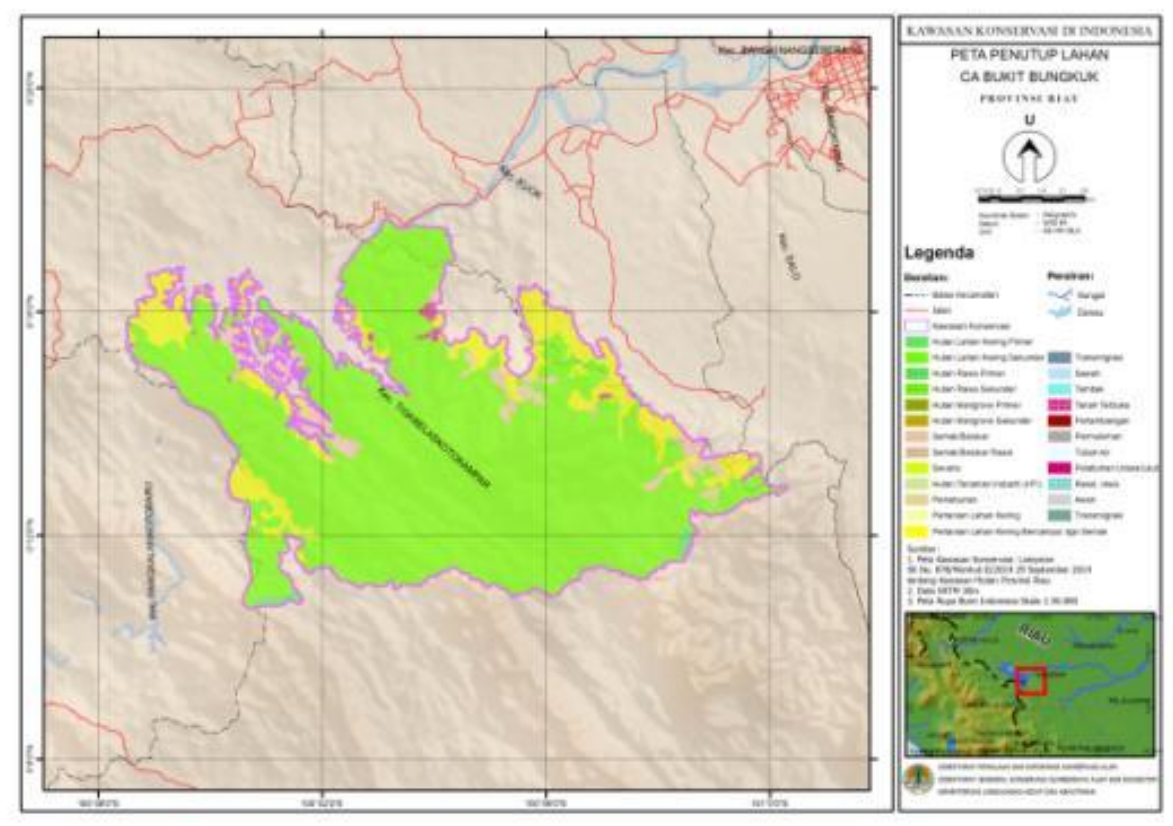

Gambar 1. Peta CA Bukit Bungkuk

Pengelolaan CA. Bukit Bungkuk senantiasa memperhatikan aspek - aspek keanekaragaman hayati, gangguan kawasan, daya tarik atau perhatian masyarakat dan aksesibilitas. Pemantauan berkala dilaksanakan secara periodik untuk mendeteksi secara dini adanya perkembangan suksesi dan atau potensi ancaman. Dengan pemantauan berkala ini setidaknya dapat diketahui secara faktual dan terkini terkait kondisi yang ada. Menurut Carwardine et al. (2012) menyatakan pengelolaan potensi ancaman sebagai sebuah sistem pendeteksian dini dapat menjaga keberadaan habitat alam liar sebagai bentuk konservasi jangka panjang.

Menuju CA. Bukit Bungkuk dapat ditempuh dari Kota Pekanbaru melalui jalur darat sekitar 2 jam melalui Kota Bangkinang. Selanjutnya, akses ke dalam kawasan CA. Bukit Bungkuk ditempuh menggunakan jalan darat dan jalan air dengan dengan jarak tempuh sekitar 2 - 3 jam. Untuk mobilitas relatif terjangkau dan mudah diakses sehingga menjadi sebuah peluang maupun tantangan dalam pengelolaannya.

Secara topografi kawasan CA. Bukit Bungkuk mempunyai kemiringan sangat curam hingga landai. Dapat dirinci topografi sangat curam (>60\%) sekitar $60 \%$ dari wilayah, kemiringan hingga sangat curam (41-60\%) yang meliputi $30 \%$ kawasan dan $10 \%$ wilayah berkemiringan landai sampai agak curam (9 $25 \%$ ). Secara umum CA. Bukit Bungkuk umumnya berada pada ketinggian antara $100-500 \mathrm{mdpl}$.

Struktur geologi pada kawasan CA. Bukit Bungkuk mengalami pelapukan intensif dan pengikisan yang membentuk jenis tanah yang sebagian besar adalah Tropudult (USDA, 1975) setara dengan Podsolik Merah Kuning. Kondisi ini umum ditemukan pada bagian punggung bukit. Pelapukan intensif dan pengikisan lainnya membentuk tanah Dystropepts atau setara dengan Latosol pada bagian lereng bukit dan 
membentuk tanah Ustrocrepts pada bagian lembah. Tipe tanah ini mencirikan tanah yang baru berkembang dan telah berkembang lanjut serta dikategorikan rawan terhadap erosi maupun longsor.

Berdasarkan klasifikasi curah hujan menurut Schmidt dan Ferguson (1951), kawasan CA. Bukit Bungkuk termasuk ke dalam tipe iklim A $(\mathrm{Q}=0 \%)$ yakni termasuk dalam iklim sangat basah. Rerata bulan basah sebanyak 10 bulan setiap tahunnya yang mana hujan terjadi sepanjang tahun, tanpa terdapat bulan kering. Pada kriteria bulan basah memiliki curah hujan $>100 \mathrm{~mm}$, sedangkan bulan kering $<60 \mathrm{~mm}$ dengan curah hujan tahunan berkisar dari 1218,1 mm sampai $2104 \mathrm{~mm}$, sedangkan curah hujan rata - rata tahunan sebesar 1662,4 mm/tahun.

Kawasan CA. Bukit Bungkuk termasuk ke dalam Daerah Aliran Sungai (DAS) Kampar yang mengalir sungai - sungai kecil, seperti Sungai Arau Besar, Sungai Arau Kecil, Sungai Parancaman, Sungai Batul, Sungai Pantian, Sungai Gading serta Sungai Batang Mahat. Dari sudut pandang hidrologi belum mencerminkan kesatuan daerah tangkapan air secara utuh sebagai bagian integral dari Sub DAS Kampar Kanan. Lebih lanju, kawasan CA. Bukit Bungkuk merupakan catchment area dan terdapat aliran - aliran sungai yang mengalir dan bermuara ke genangan PLTA Koto Panjang. Namun, terdapat juga aliran yang dapat mengarah ke areal permukiman masyarakat. Untuk debit air, pada musim kemarau dikategorikan debit aliran rendah sedangkan pada musim hujan dikategorikan debit aliran puncak. Secara ekologis CA. Bukit Bungkuk memainkan peran sebagai pemegang dan penyimpan limpasan air hujan pada bagian hulu DAS Kampar.

\section{Potensi Flora dan Fauna}

Kawasan CA. Bukit Bungkuk dengan habitat hutan dataran rendah primer dan sekunder memiliki berbagai keunikan alam termasuk flora dan faunanya. Di kawasan CA. Bukit Bungkuk dapat ditemukan beberapa jenis tanaman kayu diantaranya Kempas (Koompassia malaccensis), Keruing (Dypterocarpus borneensis), Kulim (Scorodocarpus borneensis), Tampui (Elateriospermum tapos), Gelam (Melaleuca leucadendron), Balam (Palaquium walsurifolium), Meranti merah (Shorea acuminata), Pasak bumi (Eurycoma longifolia), Rengas (Gluta rengas), Tembesu (Fragraea fragrans), dan Terap (Artocarpus sp). Selain itu yang sangat langka adalah ditemukannya keberadaan bunga bangkai (Amorphophallus gigas). Lokasi penemuan bunga bangkai ini berada pada Desa Bukit Melintang dan Desa Merangin Kec. Kuok (Gambar 2). Pada Desa Bukit Melintang ditemukan sebanyak 2 individu secara bersamaan, sedangkan pada Desa Merangin ditemukan sebanyak 1 individu.

Hartini \& Wawaningrum (2011) mempublikasikan tanaman anggrek di kawasan CA. Bukit Bungkuk berdasarkan inventarisasinya menemukan 20 jenis. Anggrek tersebut terdiri atas 14 jenis anggrek epifit dan 6 jenis anggrek terrestrial. Jenis - jenis anggrek terestrial, yakni (Liparis rheedii (Blume) Lindl., Corymborkis veratrifolia Lind1., Eulophia spectabilis (Dennst.) Suresh, Renanthera elongata Blume, Dipodium paludosum (Griff.) Rchb.f. dan Aphyllorchis pallida Blume. Renanthera dan Dipodium seringkali merupakan anggrek terrestrial pada awal pertumbuhannya. Terdapat juga 14 jenis anggrek epifit, yakni (Coelogyne rochussenii De Vriese, Coelogyne foerstermannii Rchb.f., Bulbophyllum sp., Bulbophyllum odoratum (Blume) Lindl., Dendrobium connatum (Blume) Lindl., Dendrobium salaccense (Blume) Lindl., Dendrobium leonis (Lindl.) Rchb.f., Epigenium sp., Pomatocalpa spicata Breds., Cymbidium finlaysonianum Lindl., Cymbidium bicolor Lindl., Gastrochillus sp., Dendrobium crumenatum Sw. dan Acriopsis lilifolia (Koen.) Ormerod. Kawasan Bukit Bungkuk bukan merupakan habitat yang sesuai untuk sebagian besar jenis anggrek, karena kawasan ini kondisinya sangat panas dan kurang lembab.

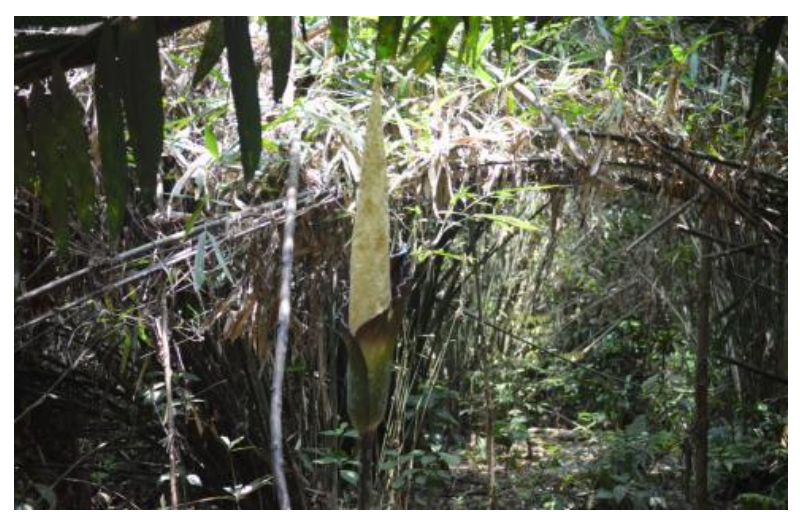

Gambar 2. Bunga Bangkai (Amorphophallus gigas) di CA. Bukit Bungkuk 


\section{ZONA}

Jurnal Lingkungan

ISSN : 2502-6496 (Print)

Volume 3, No 1, April 2019, p. 1-9

http://zona.pelantarpress.co.id

Selain keanekaragaman jenis flora, kawasan CA. Bukit Bungkuk juga memiliki keanekaragaman satwa liar yang tinggi. Beberapa jenis satwa liar yang dijumpai secara langsung dan tidak langsung (jejak kaki dan suara), yakni Harimau sumatera (Panthera tigris sumatrae), Rusa (Cervus timorensis), Tapir (Tapirus indicus malayensis), Burung Enggang (Buceros rhinoceros), Srigunting (Dicrurus annectans), dan Elang hitam (Spizaetus bartelsi), Beruang madu (Helarctos malayanus), Kijang (Muntiacus muntjac), Kancil (Tragulus javanicus), Ungko (Hylobates agilis), Simpai (Presbytis melalophos bicolor), Bajing Kelapa (Callosciurus notatus), Burung Elang-alap Jambu (Accipiter trivirgatus), Burung Rangkong (Buceros sp.), Burung Prenjak Daun (Phylloscopus trivirgatus), Burung Cabak Kota (Caprimulgus affinis), serta Burung Punai Daun (Treron olax). Beberapa fauna yang ditemukan di CA Bukit Bungkuk terlihat pada Gambar 3 dan Gambar 4.

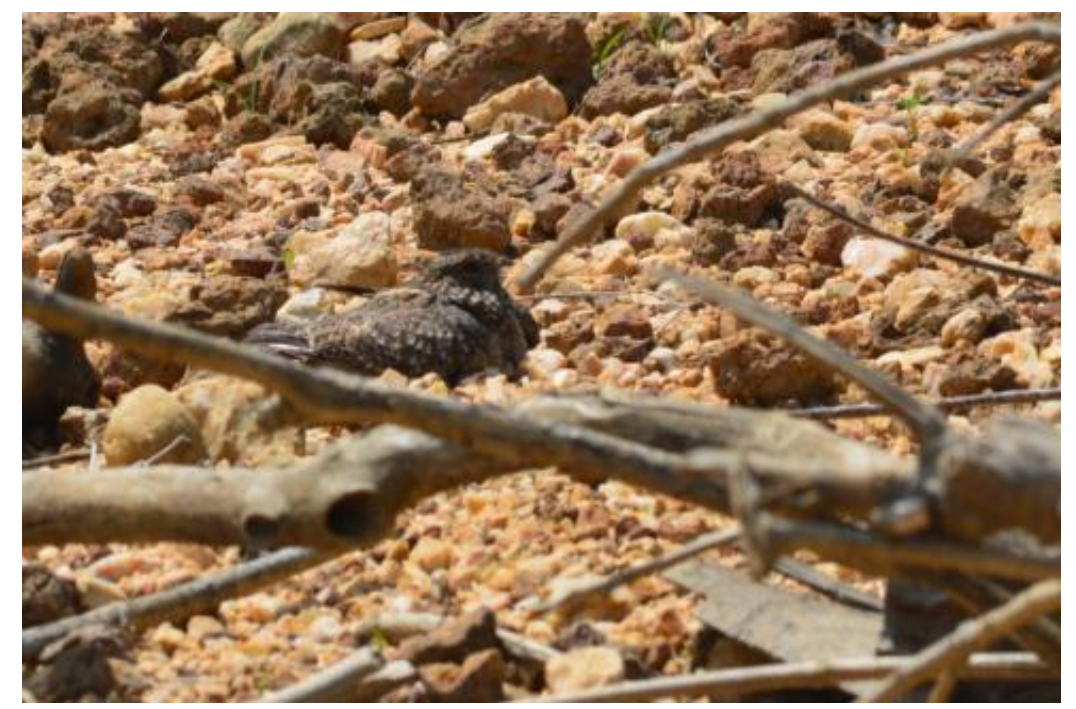

Gambar 3. Burung Cabak Kota (Caprimulgus affinis)

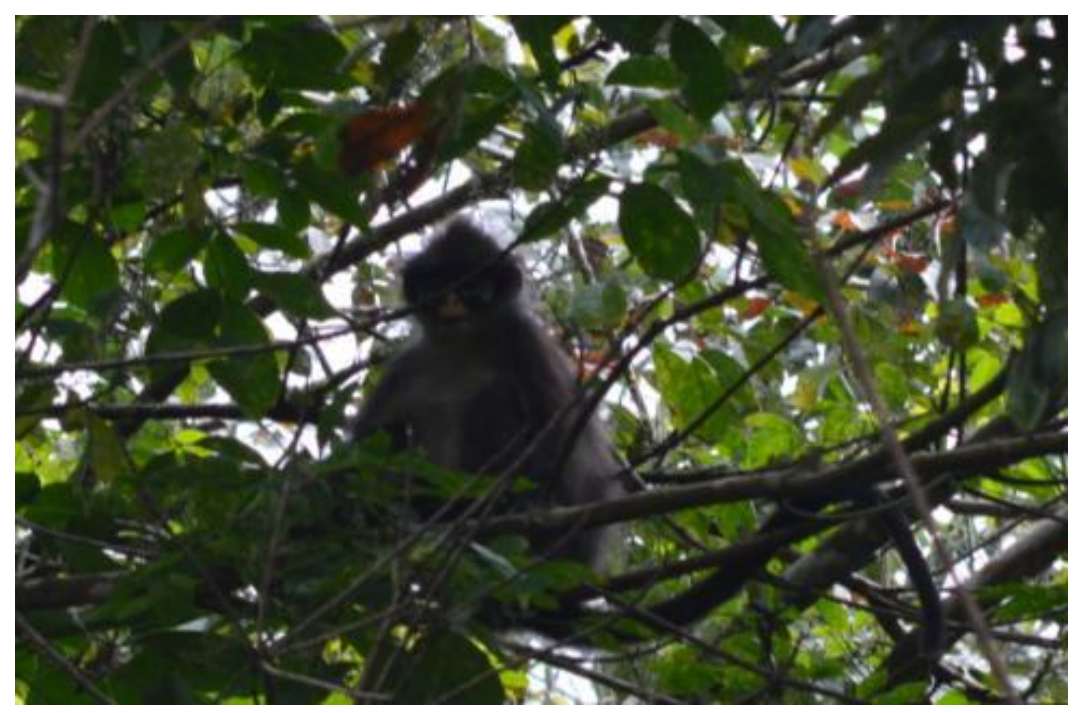

Gambar 4. Simpai (Presbytis melalophos bicolor)

Pengklasifikasian terkait status kelangkaan keanekaragaman jenis satwa liar yang terdapat dalam kawasan CA. Bukit Bungkuk disajikan pada Tabel 1. 
Tabel 1. Keanekaragaman Jenis Satwa Liar di CA. Bukit Bungkuk

\begin{tabular}{|c|c|c|c|c|c|}
\hline No & Nama Indonesia & Nama Inggris & Nama Ilmiah & $\begin{array}{l}\text { Status } \\
\text { IUCN }\end{array}$ & $\begin{array}{c}\text { PP } \\
7 / 1999\end{array}$ \\
\hline 1. & $\begin{array}{c}\text { Burung Elang-alap } \\
\text { Jambu }\end{array}$ & Crested Goshawk & Accipiter trivirgatus & $\mathrm{LC}$ & $\mathrm{P}$ \\
\hline 2. & Burung Sempidan Biru & Crested fireback & Lophura ignita & NT & NP \\
\hline 3. & $\begin{array}{c}\text { Burung Sempidan } \\
\text { Merah }\end{array}$ & Crestless fireback & $\begin{array}{c}\text { Lophura } \\
\text { erythrophthalma }\end{array}$ & VU & NP \\
\hline 4. & Burung Kuau Raja & Bird Great argus & Argusianus argus & NT & $\mathrm{P}$ \\
\hline 5. & Burung Punai Daun & $\begin{array}{c}\text { The Little Green } \\
\text { Pigeon }\end{array}$ & Treron olax & $\mathrm{LC}$ & NP \\
\hline 6. & Burung Cabak Kota & Savannah Nightjar & Caprimulgus affinis & $\mathrm{LC}$ & NP \\
\hline 7. & Burung Prenjak Daun & $\begin{array}{l}\text { Mountain leaf } \\
\text { warbler }\end{array}$ & $\begin{array}{c}\text { Phylloscopus } \\
\text { trivirgatus }\end{array}$ & $\mathrm{LC}$ & NP \\
\hline 8. & Simpai & Mitred Leaf Monkey & $\begin{array}{c}\text { Presbytis melalophos } \\
\text { bicolor }\end{array}$ & EN & $\mathrm{P}$ \\
\hline 9. & Ungko & Agile gibbon & Hylobates agilis & EN & $\mathrm{P}$ \\
\hline 10. & Landak & Common porcupine & Hystrix brachyura & $\mathrm{LC}$ & $\mathrm{P}$ \\
\hline 11. & Pelanduk & Mouse deer & Tragulus sp. & $\mathrm{LC}$ & $\mathrm{P}$ \\
\hline 12. & Beruk & Pig tailed macaque & Macaca nemestrina & VU & NP \\
\hline 13. & Angkis Ekor Panjang & $\begin{array}{l}\text { Long tailed } \\
\text { porcupine }\end{array}$ & Trichys fasciculata & $\mathrm{LC}$ & NP \\
\hline 14. & Trenggiling & Sunda pangolin & Manis javanica & $\mathrm{CR}$ & $\mathrm{P}$ \\
\hline 15. & Bajing & Squirrel & - & $\mathrm{LC}$ & NP \\
\hline 16. & Tikus & Rat & - & $\mathrm{LC}$ & NP \\
\hline 17. & Kijang & Barking deer & Muntiacus muntjac & $\mathrm{LC}$ & $\mathrm{P}$ \\
\hline 18. & Tapir & Malayan tapir & Tapirus indicus & EN & $\mathrm{P}$ \\
\hline 19. & Rusa Sambar & Sambar deer & Rusa unicolor & VU & $\mathrm{P}$ \\
\hline 20. & Babi Hutan & Wild pig & Sus scrofa & $\mathrm{LC}$ & NP \\
\hline 21. & Macan Dahan & Clouded leopard & Neofelis diardi & VU & $\mathrm{P}$ \\
\hline 22. & Ajag/Anjing Hutan & Dhole & Cuon alpinus & EN & $\mathrm{P}$ \\
\hline 23. & Beruang Madu & Malayan sun bear & Helarctos malayanus & VU & $\mathrm{P}$ \\
\hline 24. & Harimau Sumatera & Sumatran tiger & $\begin{array}{c}\text { Panthera tigris } \\
\text { sumatrae }\end{array}$ & $\mathrm{CR}$ & $\mathrm{P}$ \\
\hline 25 . & Linsang & Banded linsang & Prionodon linsang & $\mathrm{LC}$ & $\mathrm{P}$ \\
\hline 26. & Musang Belang & Banded palm civet & Hemigalus derbyanus & NT & NP \\
\hline 27. & Binturong & Binturong & Arctictis binturong & VU & $\mathrm{P}$ \\
\hline 28. & Kucing Emas Asia & Golden cat & Catopuma temminckii & NT & $\mathrm{P}$ \\
\hline 29. & Kucing Hutan & Leopard cat & Felis bengalensis & $\mathrm{LC}$ & $\mathrm{P}$ \\
\hline 30. & Kucing Batu & Marbled cat & Felis marmorata & VU & $\mathrm{P}$ \\
\hline 31. & Musang Bulan & Masked palm civet & Paguma larvata & $\mathrm{LC}$ & NP \\
\hline 32. & Musang Leher Kuning & $\begin{array}{c}\text { Yellow throated } \\
\text { marten }\end{array}$ & Martes flavigula & $\mathrm{LC}$ & NP \\
\hline
\end{tabular}

Keterangan : LC (Least Concern), NT (Near Threatened), VU (Vulnerable), CR (Critically Endangered), EN (Endangered), P (Dilindungi), NP (Tidak Dilindungi).

Keberadaan tumbuhan dan satwa dilindungi di dalam kawasan CA. Bukit Bungkuk menunjukkan bahwa fungsi kawasan cagar alam dalam rangka pengawetan keanekaragaman flora dan fauna berjalan dengan baik. Penetapan kawasan CA. Bukit Bungkuk sebagai rumah bagi tumbuhan dan satwa liar secara tidak langsung menuntut menajemen dalam dimensi ruang dan waktu yang saling bersinergi. Memberikan 


\section{ZONA}

Jurnal Lingkungan

Volume 3, No 1, April 2019, p. 1-9

ISSN : 2502-6496 (Print)

http://zona.pelantarpress.co.id

kawasan sebagai habitat sebagai upaya pelestarian dilakukan dalam rangka menjaga dan mengontrol populasi guna mempertahankan keberadaannya secara ekologi.

Menurut Kusumawati dan Sardjana (2011), menjelaskan manajemen tumbuhan dan satwa liar hendaknya mengacu pada lima pilar yaitu terbebas dari lapar dan haus, bebas dari penyebaran penyakit, bebas dari penganiayaan, bebas berperilaku secara alami dan bebas dari perburuan. Pengelolaan manajemen ancaman prioritas untuk keragaman hayati dilakukan dengan mengkalkulasikan keuntungan terhadap biodiversitasnya atas biaya preventif dan kuratif terhadap ancaman yang akan menjadi hambatan (Carwardine et al., 2018).

Disamping itu, beberapa jenis primata dan herbivora yang ada berperan juga dalam melakukan penyebaran benih - benih tumbuhan di dalam kawasan Cagar Alam Bukit Bungkuk dalam perspektif rantai makanan pada sebuah ekosistem. Menurut Irwan (2012), interaksi antar organisme dalam sebuah ekosistem tidak terlepas dari karakteristiknya dalam sebuah rantai makanan.

Selanjutnya kemampuannya beradaptasi terhadap faktor pembatas lingkungan membuatnya dapat mempertahankan jenis dalam lingkup individu hingga komunitas. Secara detail Garsetiasih dan Heriyanto (2017) menyampaikan kondisi alam dengan kemampuannya untuk mendukung ritme hidup organisme diatasnya dapat dikalkulasikan dengan pendugaan melalui pendekatan faktor-faktor ketersediaan pakan, luas tutupan lahan, daerah jelajah satwa dan kebutuhan pakan perorganisme dalam sebuah populasi.

Lebih lanjut, Marwa et al. (2020) mempublikasikan mengenai adanya kebijakan perubahan status kawasan hutan menjadi peruntukan lainnya menjadi salah satu pemicu penurunan daya dukung bioekologi hutan.

\section{Potensi Jasa Lingkungan}

Potensi jasa lingkungan yang dapat dimanfaatkan di kawsan CA Bukit Bungkuk berupa pemanfaatan karbon. Kondisi ini mengacu pada Peraturan Pemerintah No. 28 Tahun 2011 yang mana kawasan CA Bukit Bungkuk hanya dapat dimanfaatkan untuk kegiatan penelitian dan pengembangan ilmu pengetahuan, pendidikan dan peningkatan kesadartahuan konservasi alam, penyerapan dan/atau penyimpanan karbon dan pemanfaatan sumber plasma nutfah untuk penunjang budidaya. Selanjutnya untuk mengoptimalkan pemanfaatan jasa lingkungan diupayakan untuk mengintegrasikan potensi potensi jasa lingkungan lainnya ke dalam kawasan CA. Bukit Bungkuk. Potensi - potensi tersebut meliputi:

\section{Waduk Koto Panjang}

Kawasan CA. Bukit Bungkuk memiliki keunikan dengan kawasan konservasi lainnya di Provinsi Riau, dimana di sekitar kawasan terdapat waduk yang digunakan sebagai sumber pembangkit listrik tenaga air (PLTA). Waduk PLTA Koto Panjang memiliki peranan yang sangat penting untuk pembangkit listrik tenaga air, transportasi dan wisata di Provinsi Riau. Keberadaan waduk Koto Panjang memiliki panorama alam yang indah dengan latar deretan bukit-bukit yang ditumbuhi berbagai jenis pepohonan, yang salah satunya adalah bagian dari Cagar Alam Bukit Bungkuk (Gambar 5).

Kawasan CA. Bukit Bungkuk merupakan catchment area bagi kawasan waduk Koto Panjang, sehingga kelestarian kawasan ini sangat berkaitan dengan keberlangsungan sumber air bagi PLTA Koto Panjang. Rusaknya kawasan CA. Bukit Bungkuk dapat menyebabkan terjadinya erosi pada saat hujan yang mengakibatkan pendangkalan pada waduk dan pada saat musim hujan mampu menyebabkan terjadinya kebanjiran di sekitar wilayah waduk. Disamping itu, pada musim kemarau akan menyebabkan terjadinya kekeringan dikarenakan ketiadaan penyimpan air tanah. 


\section{ZONA}

Jurnal Lingkungan ISSN : 2502-6496 (Print)

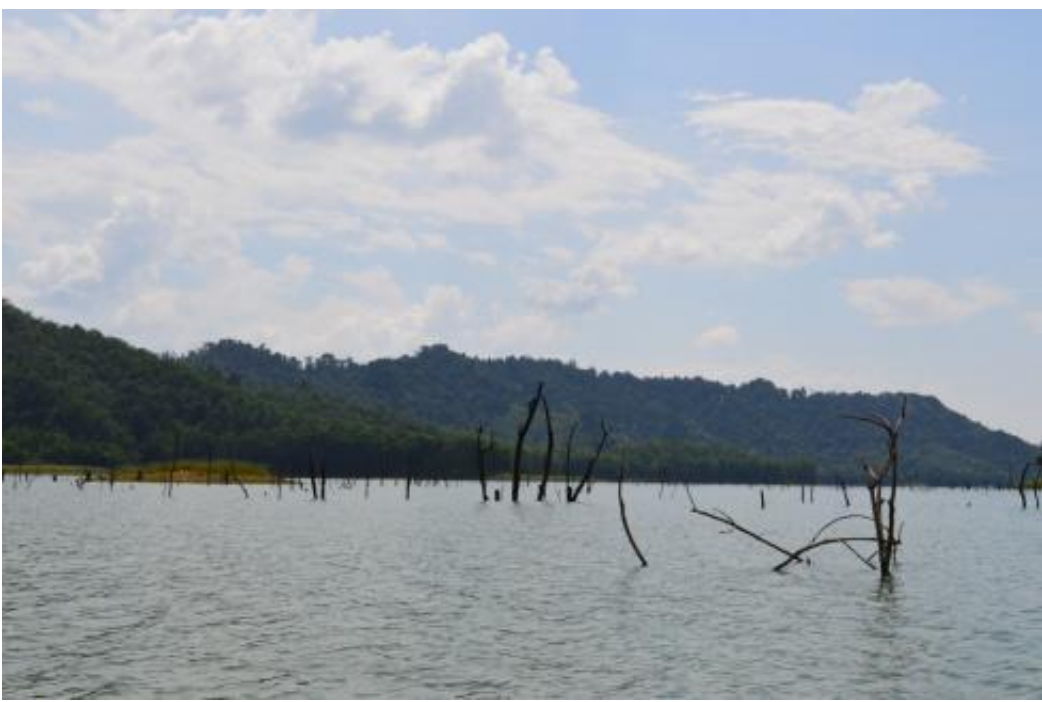

Gambar 5. Sebagian Waduk Koto Panjang di dalam wilayah CA. Bukit Bungkuk

Rosalina et al. (2014) menjelaskan Waduk Koto Panjang dapat dikembangkan sebagai daerah tujuan wisata di Provinsi Riau. Secara teknis dapat dilakukan dengan menetapkan zonasi untuk konservasi dan pemanfaatan yang dilanjutkan dengan komitmen Pemerintah Daerah dengan masyarakat tempatan untuk mempromosikan dan mengelolanya sebagai sebuah objek wisata alam.

Menurut Diarto et al. (2012) bentuk partisipasi masyarakat dalam pemanfaatan sumber daya alam yang dalam hal ini adalah jasa lingkungan berupa partisipasi sukarela atau swakarsa. Faktor lain yang sangat berpengaruh terhadap persepsi masyarakat itu sendiri adalah tingkat pendidikan. Ketika mereka sadar akan peran kawasan konservasi sebagai penyangga kehidupan, maka dengan sendirinya mereka akan menjaga, melestarikan dan merawat sumber daya alam tersebut.

\section{Air Terjun}

Pada kawasan CA. Bukit Bungkuk terdapat beberapa air terjun yang memiliki tinggi bervariasi antara \pm 2 meter dan \pm 3 meter. Keberadaan air terjun ini merupakan konsekuensi atas limpasan hidrologis air pada bagian hulu yang masih berhutan. Keberadaannya sebagai pemegang dan penyimpan air tanah membentuk aliran air secara alami didukung oleh struktur geologi lainnya. Kondisi topografi yang berbukit - bukit dengan kondisi yang curam, membentuk air terjun pada aliran sungai yang berada di dalam kawasan CA. Bukit Bungkuk (Gambar 6).
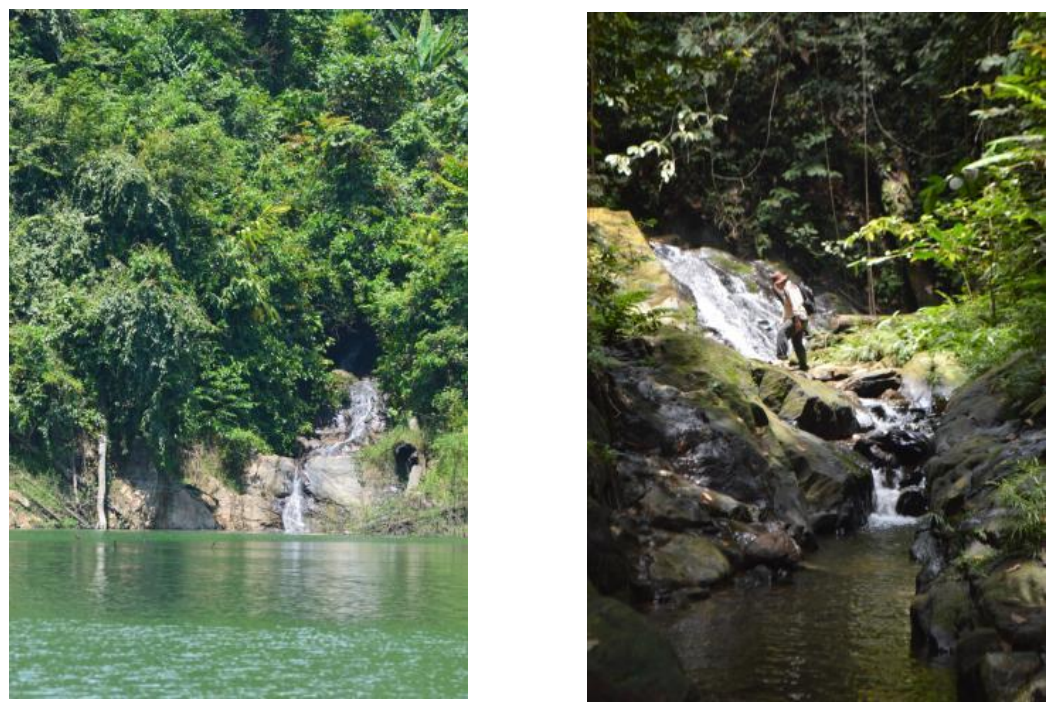

Gambar 6. Bebeapa air terjun di sekitar kawasan CA. Bukit Bungkuk 
Pada kawasan CA. Bukit Bungkuk terdapat banyak sungai - sungai yang mengalir di dalam kawasan. Pada saat hujan, sungai yang berada di dalam kawasan naik hingga \pm 1 meter. Hal ini akan sangat berbahaya saat pada bagian puncak - puncak bukit di CA. Bukit Bungkuk mengalami penggundulan dapat berakibat terjadinya banjir besar yang membawa kayu - kayu bekas penebangan liar atau pohon - pohon di bukit yang kita kenal sebagai banjir bandang. Kondisi ini tentunya terjadi ketika sebuah ekosistem telah rusak sehingga menjadi sebuah bencana ekologis.

Menurut Alikodra (2012), upaya penyelamatan sumber daya alam diperlukan kecermatan dalam menghitung potensi, penyebaran dan sifat alamiah sumber daya yang ada serta diselaraskan dengen pertumbuhan manusia yang ada. Dalam implementasinya diperlukan penyamaan perspektif yang meliputi ekologi, ekonomi dan sosial. Kompilasi ketiga faktor tersebut akan menjadi parameter dalam paradigma pembangunan berkelanjutan nantinya.

Disisi lain, keefektifan pembayaran kompensasi atas jasa lingkungan yang diterima masih ditemukan kebiasan data. Hal ini menuntut penguatan secara empiris pada dimensi kontekstual dan skema desain (Borner et al. 2017). Sedangkan Zhang et al. (2019) menegaskan mengenai optimalisasi pemanfaatan sumber daya air harus memperhatikan skema tingkat pengembangan sosial ekonomi, pengaturan daerah luasan berdampak langsung secara komprehensif dan tingkat kepedulian terhadap ekologi perairan.

Sejalan dengan hal tersebut, Fadeli dan Muhammad (2009) menjelaskan upaya komprehensif mengkonservasi lanskap yang mencakup identifikasi keberadaan dan permasalahan lanskap (fisik, biotis, sosial \& budaya), inventarisasi potensi lanskap dalam penyokong antropologi, perencanaan pengembangan lanskap berdasarkan kebutuhan \& fungsinya dan penetapan arah dan strategi pengembangan lanskap.

\section{KESIMPULAN}

Kawasan CA Bukit Bungkuk terdapat 32 jenis satwa liar yang ditemukan secara langsung ataupun tidak langsung dengan sebanyak 7 jenis burung dan 25 jenis mamalia. Dari kedua puluh jenis satwa liar tersebut, sebanyak 19 jenis (17 jenis mamalia dan 2 jenis burung) diklasifikasikan sebagai satwa liar dilindungi berdasarkan Peraturan Pemerintah No. 7 Tahun 1999. Terdapat 2 potensi jasa lingkungan di Kawasan CA. Bukit Bungkuk yang dapat dikembangkan dalam rangka pemberdayaan masyarakat di sekitar kawasan, yakni waduk koto panjang dan air terjun yang terdapat pada beberapa titik di dalam kawasan. Upaya penataan dan pengembangan kawasan untuk keperluan konservasi tumbuhan dan satwa liar beserta pemanfaatan jasa lingkungan dilakukan berdasarkan regulasi yang ada dan dalam konteks konservatif dan berkelanjutan.

\section{UCAPAN TERIMA KASIH}

Penulis mengucapkan terimakasih dan apresiasi kepada seluruh jajaran manajemen Balai Besar Konservasi Sumber Daya Alam khususnya pada Kantor Resort Kampar yang telah membantu secara teknis kegiatan pengumpulan data melalui patroli di CA. Bukit Bungkuk. Lebih lanjut kepada segenap fungsional peneliti dan teknisi litkayasa pada Balai Penelitian dan Pengembangan Teknologi Serat Tanaman Hutan. Makalah ini setidaknya akan menjadi sejarah bahwa kita pernah berbuat untuk sebuah konservasi agar pengelolaan sumber daya alam ini dapat terwarisi kepada generasi setelah kita.

\section{DAFTAR PUSTAKA}

Alikodra H.S. 2012. Konservasi Sumber Daya Alam dan Lingkungan : Pendekatan Ecoshopy bagi Penyelamatan Bumi. Yogyakarta. Gadjah Mada University Press.

Borner J., baylis K., Corbbera E., De-Blas D. E., Roses J.H., Persson M., Wunder S. 2017. The Effectiveness of Payments for Environmental Services. World Development: 03-16.

Carwardine J., O'cornor T., Legge S., Mackey B., Possingham H.P., Martin T.G., 2012. Prioritizing Threat Management for Biodiversity Conservation. Conservation Letters (5): 196-204.

Carwardine J., Martin T., Firn J., Reyes R.P., Nicol S., Reeson A., Grantham H.S., Stratford D., Kehoe L., Chades I., 2018. Prioritizing Threat Management for Biodiversity Conservation:A hanbook. Journal of Applied Ecology: 01-10. 


\section{ZONA}

Jurnal Lingkungan

ISSN : 2502-6496 (Print)
Volume 3, No 1, April 2019, p. 1-9 http://zona.pelantarpress.co.id

Diarto, Hendrarto B., Suryoko S. (2012). Partisipasi Masyarakat dalam Pengelolaan Lingkungan Kawasan Hutan Mangrove Tugurejo di Kota Semarang. Jurnal Ilmu Lingkungan. Volume 10 (1): 1 - 7.

Fandeli C. dan Muhammad. 2009. Prinsip-Prinsip Dasar Mengkonservasi Lanskap. Yogyakarta. Gadjah Mada University Press.

Garsetiasih R. dan Hariyanto N.M. 2017. Potensi Hutan Reklamasi Bekas Tambang Batu Bara Sangata Kalimantan Timur untuk Penangkaran Rusa Sambar (Rusa unicolor). Buletin Plasma Nutfah 23 (2): $127-136$.

Hartini S, Wawangningrum, H. 2011. Keragaman Anggrek Alam di Kawasan Konservasi Bukit Bungkuk, Kabupaten Kampar, Provinsi Riau. Konservasi Tumbuhan Tropika: Kondisi Terkini dan Tantangan ke Depan. Prosiding Seminar/UPT Balai Konservasi Tumbuhan. - Cibodas. 140 - 143.

Irwan Z.D., 2012. Prinsip-Prinsip Ekologi Ekosistem, Lingkungan dan Pelestariannya. Yogyakarta, Gadjah Mada University Press.

Kusumawati D. dan Sardjana I.K.W., 2011. Bahan Ajar Satwa Liar, Yogyakarta: Gadjah Mada University Press.

Marwa J., Sineri A.S., Hematang F. 2020. Daya Dukung Bioekologi Hutan dan Lahan di Kabupaten Manokwari, Provinsi Papua Barat. Jurnal Sylva Lestari. Volume 8 (2): 197 - 206.

Rosalina H, Sujianto, Siregar SH. 2014. Strategi Pengembangan Ekowisata di Kawasan Waduk Pembangkit Listrik Tenaga Air (PLTA) Koto Panjang Kabupaten Kampar. Jurnal Dinamika Lingkungan Indonesia. 1(2) : 97 - 108.

Zhang J., Zhang G., Shi W., Fu Y. 2019. Quantitative Evaluation and Optimized Utilization of Water Resources Environment Carrying Capacity Based on Nature-Based Solution. Journal of Hydrology 528: 96-107. 